Nadira A Hatim 1 BDS, MSc (Assist Prof)

Rawa Y Al-Rawee ${ }^{2}$ BSc, MSc (Senior Spec)

Bashar A Tawfeeq ${ }^{2}$ BDS, FICMS (Spec)

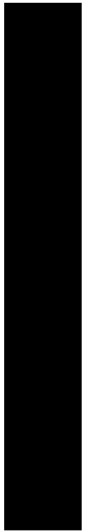

\section{Criteria for selection of Implant cases}

\author{
1Department of Prosthetic Dentistry \\ College of Dentistry, University of Mosul
}

2Ninevah Health Directorate

Ministry of Health

\begin{abstract}
Aims: To evaluate upper and lower limits of the parameters used such as (age, sex, or selection of patient), and to detect the grade of understanding and acceptance of Iraqi publics for the implant surgery (education level). Materials and Methods: From a total of 300 patients seeking implant therapy in Al-Salam Hospital Implantology Center, only 45 patients were chosen to undergo implant surgery with age group 17->60 years during the period from February 2002 to February 2005. A case sheet was specially prepared for this study containing information needed to determine the suitable criteria of implantation. Frialit-2 implant system was used with its different lengths and widths (colorcoded). Maxillary and mandibular impressions, registration of maxillo-mandibular jaw relation records were done for each patient to record all findings. Data were collected and statically analyzed. Results: The higher age group patients were 17-30 years with percentage 5.33\%, while non-operated patients 51-60 years showed high percentage of $29.66 \%$. Criteria of the forty five patients (22 females and 23 males) participated in this study were statistically analyzed concerning the economical level. The operated patients showed 57.77\% level I (high), 40\% level II (moderate) and 2.22\% level III (low). While for education level showed 53.3\% level I, 42.2\% level II and 4.4\% level III. Conclusion: Low percentage of educational level of patients need an explanation about surgical and prosthetic parts of dental implant to elevate the education level of patients. In addition to educational level, economical level of patient plays an important role in the criteria for selection of patients.

Key Words: Implant selection, education of patient, economical level.
\end{abstract}

Hatim NA, Al-Rawee RY, Tawfeeq BA. Criteria for selection of Implant cases. Al-Rafidain Dent J. 2006; 6(2): 161-170.

\section{INTRODUCTION}

Implant surgery is the phase of implant dentistry concerning the selection, planning and placement of the implant body and abutment. While implant prosthodontics is the phase of prosthodontics concerning the replacement of missing teeth and/or associated structures by restorations that are attached to dental implants. ${ }^{(1)}$ For centuries, even the best dentists could not help; they had ways and means to replace the tooth crown but not the root. But time has changed, for about twenty years, dentists have been able to "get to the root" of gaps between the teeth by replacing the missing roots with tiny pins called "implants".

Dental implant was classified in relation to the bone into: ${ }^{(2)}$

1. Subperiosteal implant. ${ }^{(3)}$
2. Transosteal implant. ${ }^{(4)}$

3. Endosteal implant: This type is placed in the bone (alveolar or basal) of both mandible and maxilla, and transitioning only one cortical plate. ${ }^{(1)}$ This type can be classified to root form or blade form. ${ }^{(2)}$

The goal of modern dentistry is to restore normal contour, function, esthetic, speech, comfort and health regardless of atrophy, disease or injury of the stomatognathic system.

The International Team of Implantology (ITI) is a group of doctors which aim to promote study, experimental research, practical and esthetic exchange of experience in the field of oral implant. ${ }^{(5)}$

The increased needs for implantrelated service result from the combined 
effect of a number of factors: ${ }^{(6)}$

1. Age related loss of teeth.

2. Anatomic condition of edentulous ridge.

3. Psychological need of the patient.

4. Reduced performance of removable prosthesis.

5. Increased awareness of the benefit of implant by professionals, and the publics.

Dental implants are intended to be used in single tooth restoration, edentulous spans restored with multiple single teeth, free standing bridges and to retain overdentures. The implants can be used for immediate or late implant placement. ${ }^{(7)}$ Implants generally look, and feel more natural than removable dentures, or bridge. They provide about the same amount of biting force as fixed bridge (much more than dentures) but are easier on surrounding teeth. ${ }^{(8)}$

This study was designed to evaluate upper and lower limits of the parameters used such as age, sex, or selection of patient for indication to implant treatments, and to detect the grade of understanding and acceptance of Iraqi publics for the implant surgery (education level).

\section{MATERIALS AND METHODS}

\section{Patient's Selection:}

From a total of 300 patients seeking implant therapy, only 45 patients were chosen to undergo implant surgery with age group range between $17->60$ years since the period from February 2002 to February 2005 in the first Center of Implantology in Al-Salam Hospital in Mosul City. Special criteria were detected when choosing the patients.

Clearly patient selection is of paramount importance when dental implants are being considered; e.g., age is one of the very important criteria. This is related to that less than 17 years when bone still growing can affect implant prosthesis. Also patients more than 50 years, most of them have medically compromising conditions which can affect implant surgery.

Other factor shared in selection is patient cooperation, which need in implant surgery as the work can exceed 8 months, also bone measurement in the site of impl- ant. $^{(6)}$

\section{Diagnosis:}

For each patient of the 45 cases, a special case sheet was prepared for this study filled with all the information needed in this paper, starting with demographic information (personal information), medical, ${ }^{(9)}$ and dental history taken, intra and extra oral examinations. All these were shown in Figure (1) (case sheet of implant in Al-Salam Center).

Each patient seeking implant treatment was examined to fit the following criteria:

\section{I- General factors:}

1. Age group.

2. Medical fitness.

3. Performance and psychology of the patient.

4. Education level and economy.

5. Habits.

II- Local factors:

1. Oral hygiene.

2. Bone measurements.

3. Time of extraction.

4. Space available for final fixture.

\section{Oral Hygiene:}

Diagnosis is based on: ${ }^{(10)}$

1. Probing to elicit bleeding (which is the single most useful indicator of disease activity), measurement of pocket depths, attachment levels and detect subgingival calculus.

2. Testing teeth for mobility and vitality.

3. Radiographic examinations.

\section{Implants:}

Frialit-2 implant system was used with its different lengths and widths (colorcoded), as it is the only system available in the center.

\section{Implant Selection:}

The most suitable type of implant needed was selected in each case alone but as a role the longest, and the wider the implant better to be used than shorter. This depends on bone quality present in the site of surgery. ${ }^{(11)}$ Selection of implant was done by: 


\begin{tabular}{||l|l|}
\hline \multicolumn{1}{|l|}{ Demographical Information: } \\
\hline Patient's No.: & File No.: \\
\hline Patient's Name: & Phone No.: \\
\hline Age: & Occupation: \\
\hline Gender: & Marital State: \\
\hline Education: & Economy: \\
\hline Habits: & Address: \\
\hline Date of Operation: & Date of Delivery of Crown: \\
\hline
\end{tabular}

\section{History:}

Medical History:

Dental History:

\section{Clinical Examination:}

Oral Hygiene:

Periodontal Condition:

State of Occlusion:

Missing Teeth:

Site of Implant:

\begin{tabular}{llllllll|llllllll}
8 & 7 & 6 & 5 & 4 & 3 & 2 & 1 & 1 & 2 & 3 & 4 & 5 & 6 & 7 & 8 \\
\hline 8 & 7 & 6 & 5 & 4 & 3 & 2 & 1 & 1 & 2 & 3 & 4 & 5 & 6 & 7 & 8
\end{tabular}

Number of Missing Teeth:

Width of Ridge:

Inter-maxillary Space:

Artificial appliances:

\section{Investigation:}

Radiographical Findings: O.P.G Periapical.

1. Distance from the crest of the ridge:
i. Maxillary Sinus.
ii. Nasal Floor.
iii. Inferior Alveolar Canal.

2. Adjacent Teeth:

3. Condition of Bone:

\section{Blood Investigations (on need):}

Diagnosis:

Prognosis:

Management:

\section{Preoperative Assessment:}

Type of Implant:

Site of Implant:

Number of Implant:

Length of Implant:

Width of Implant:

Operative Notes:

Postoperative Notes:

Follow up:

Ginqival Former:

Prosthetic Work:

Figure (1): Case sheet for implant patients in Al-Salam Center of Implantology 
I- Clinical examination of the patient: Inspection and palpation of the edentulous area was performed for:

1. Detection of any persisting pathology present.

2. Estimation of the available bone volume is performed.

3. Judgement of the inter-arch and inter-dental space to see that there is accessibility for the instruments as well as for the future prosthetic construction. ${ }^{(11)}$

II- Radiographic Examination: Intra-oral periapical radiographs provide detailed information regarding the dimensions in length and height of available bone in small sections. They are indicated during treatment planning for single tooth implant, but of limited value for more extensive edentulous sites. The paralleling technique procedure is modified that the film is positioned parallel to the final implant body position. This technique helps for:

1. Minimizing the geometric distortions.

2. Better resolution.

3. Producing anatomically true images.

Extraoral Orthopantomography (OPG) is the most utilized diagnostic element in implant dentistry. It offers many advantages:

1. Opposing landmarks are easily identified.

2. The vertical height of bone can be assessed.

3. The procedure is performed with convenience, ease and speed.

4. Gross anatomy of the jaws and any related pathologic findings could be evaluated.

So by using specially graded transparent paper on the OPG radiograph, selection of special width and length of the implant, correct positioning and number of implants were detected. By this, patient is ready to undergo implant surgery.

\section{Pre-implantation Treatment (Prosthetic Type): ${ }^{(8,9)}$}

This treatment was done for the following reasons:

1. To improve hard and/or soft tissues.
2. To evaluate esthetic and hygiene considerations.

3. To determine final vertical dimension.

5. To determine the placement of the superstructure bar.

6. To evaluate the patient's psychological health and attitude.

7. To determine conditions for the patient management.

\section{Diagnostic Cast: ${ }^{(8)}$}

Diagnostic casts mounted with an accurate record of centric jaw relationship and maxillo-mandibular occlusion on an adjustable articulator provides:

1. Edentulous ridge relationships to the adjacent teeth and opposing arch.

2. Tooth position of potential abutments, including inclination, rotation, extrusion, spacing, and esthetic considerations.

3. Tooth morphology and structures of potential abutments.

4. Direction of the force in future implant site.

5. Present occlusal scheme.

6. Edentulous soft tissue angulations, length, width, locations, and per mucosal esthetic position.

7. Inter-arch space.

8. Arch relationship.

9. Opposing dentition.

10. Existing occlusion.

11. Number of missing teeth.

12. Parallelism of abutments.

\section{Periodontal Examination: ${ }^{(10)}$}

Basic periodontal examination (BPE) is used to screen patients. It examines every tooth in the mouth except third molars with WHO periodontal probe. Six sites on each tooth were explored and the highest score per sextant recorded as follows:

$0=$ No disease.

$1=$ Gingival bleeding but no pockets.

$2=$ No pockets $>3 \mathrm{~mm}$.

$3=$ Deepest pockets 4 or $5 \mathrm{~mm}$

$4=$ One or more tooth in sextant has a pocket $>6 \mathrm{~mm}$.

\section{Education Levels:}

In relation to our community, special criteria for patients were used to divide the levels into:

I. High level (postgraduate degree). 
II. Moderate level (above secondary schools).

III. Low level (not educated).

\section{Socio-economical Levels:}

In relation to our community, special criteria for patients was used to divide the levels into:

I. High level (>500000 ID/month).

II.Moderate level (not more than 200000 ID/month).

III. Low level (<100000 ID/ month).

So by this, only 45 cases were indicated to undergo surgery. Surgery was executed under local anesthesia, flap opened, drilling done to special length and width selected for each case, suturing and then follow up.

Statistical analysis of data included descriptive; i.e., calculation of frequencies and percentages.

\section{RESULTS}

\section{Age Incidence:}

The age of the patients ranged between 17- >61 years old distributed as in Table (1). Three hundred patients were examined for implant surgery; forty five patients were fit for the criteria previously shown in Figure (2). In comparison between operated and non-operated patients, the higher age group was $17-30$ years (5.33\%), while in non-operated patients 51-60 years showed high percentage (29.66\%), while the least age group was higher than 61 years (1\%) in operated patients and $17-30$ years (6.33) in non-operated patients.

Table (1): Incidence of age group of operated and non-operated patients

\begin{tabular}{ccccccc}
\hline \multirow{2}{*}{$\begin{array}{c}\text { Age Group } \\
\text { (Years) }\end{array}$} & \multicolumn{2}{c}{$\begin{array}{c}\text { Patients } \\
\text { Operated }\end{array}$} & \multicolumn{2}{c}{$\begin{array}{c}\text { Patients not } \\
\text { Operated }\end{array}$} & \multicolumn{2}{c}{ Total } \\
\cline { 2 - 7 } & No. & $\mathbf{\%}$ & No. & $\mathbf{\%}$ & No. & $\mathbf{\%}$ \\
\hline$<\mathbf{1 6}$ & - & - & 12 & 4 & 12 & 4 \\
$\mathbf{1 7 - 3 0}$ & 16 & 5.33 & 19 & 6.33 & 35 & 11.66 \\
$\mathbf{3 1 - 4 0}$ & 11 & 3.66 & 40 & 13.33 & 51 & 16.99 \\
$\mathbf{4 1 - 5 0}$ & 12 & 4 & 58 & 19.33 & 70 & 23.33 \\
$\mathbf{5 1 - 6 0}$ & 3 & 1 & 89 & 29.66 & 92 & 30.66 \\
$>\mathbf{6 1}$ & 3 & 1 & 37 & 12.33 & 40 & 13.33 \\
\hline Total & 45 & 15 & 255 & 85 & 300 & \\
\hline
\end{tabular}

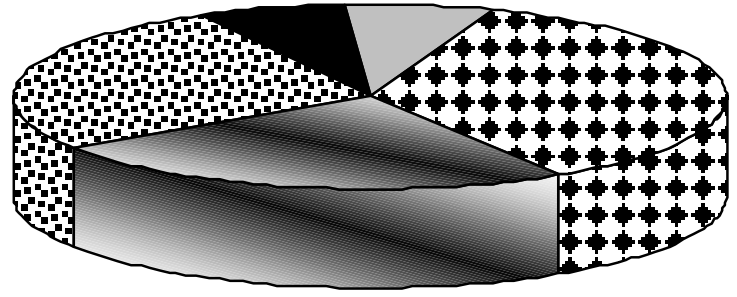

Patient Operated

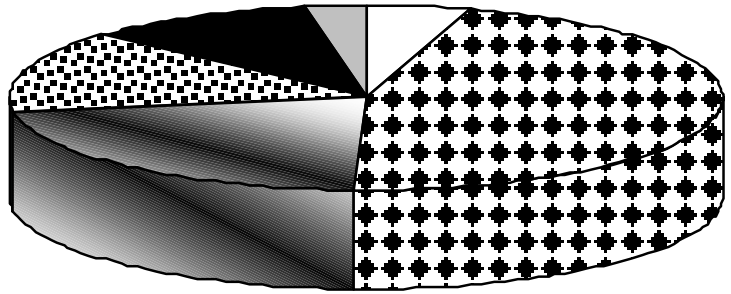

Patient Not Operated

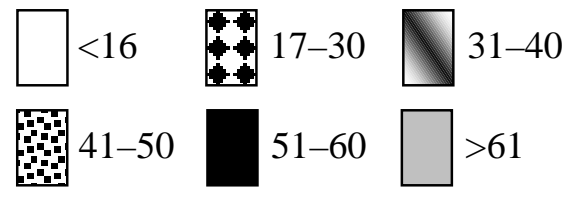

Figure (2): Incidence of Age group of operated and non -operated patients

\section{Gender Incidence:}

Twenty-two from 45 patients were females, while 23 patients were males. From the total 300 patients, 166 female pati- ents (55.33\%) seeking implant surgery, while 134 (44.66\%) were males (Table 2 and Figure 3). 
Table (2): Number and percentage of gender incidence

\begin{tabular}{ccccccc}
\hline \multirow{2}{*}{ Gender } & \multicolumn{2}{c}{ Operated } & \multicolumn{2}{c}{ Not Operated } & \multicolumn{2}{c}{ Total } \\
\cline { 2 - 7 } & No. & $\mathbf{\%}$ & No. & $\mathbf{\%}$ & No. & \% \\
\hline Male & 23 & 7.66 & 111 & 37 & 134 & 44.66 \\
Female & 22 & 7.33 & 144 & 48 & 166 & 55.33 \\
\hline Total & 45 & 15 & 255 & 85 & 300 & \\
\hline
\end{tabular}

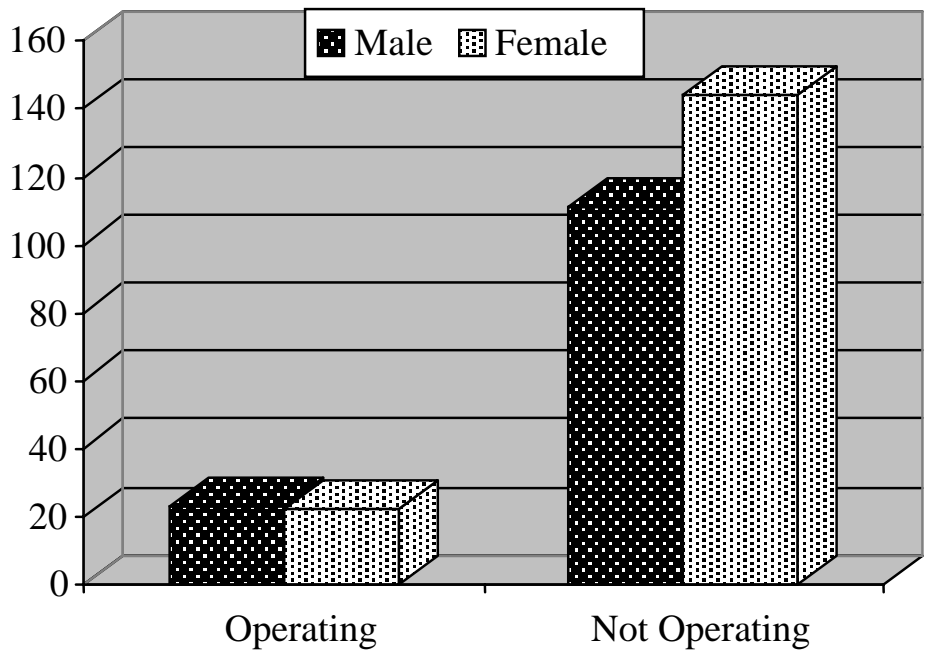

Figure (3): Gender incidence

\section{Selection of Patients:}

I. General factors: From 255 non-operated patients, 136 were unfit for surgical work due to these general factors, $8.82 \%$ were under 17 years, $30.14 \%$ preferred conservative work than surgery, and $61.02 \%$ were medically unfit. The result of this study showed high percentage $(38.55 \%)$ of patients with cardiac disease (Tables 3 and 4, and Figures 4 and 5).

II. Local factors: Bad oral hygiene constituted the highest percentage among the other factors (45.37\%) of 119 total patients while the rest distributed as fo- llows: $31.09 \%$ were non -operated due to insufficient alveolar bone width and/ or height, $12.60 \%$ due to improper inter-dental and/or inter-arch space, $10.92 \%$ due to abnormal occlusal relationship (Table 5 and Figure 6).

\section{Education and Economy:}

Statistical analysis concerning the economical levels for the operated patients showed $57.77 \%$ level I (high), $40 \%$ level II (moderate), and 2.22\% level III (low). While the education level showed 53.3\% level I, 42.2\% level II and 4.4\% level III (Table 6 and Figure 7).

Table (3): General factors of patient selection

\begin{tabular}{ccccccccc}
\hline \multirow{2}{*}{$\begin{array}{c}\text { Age Group } \\
\text { (Years) }\end{array}$} & \multicolumn{2}{c}{ Age of Patients } & \multicolumn{2}{c}{$\begin{array}{c}\text { Preferences of } \\
\text { Patients }\end{array}$} & \multicolumn{2}{c}{$\begin{array}{c}\text { Systemic Diseases } \\
\text { and Pathology }\end{array}$} & \multicolumn{2}{c}{ Total } \\
\cline { 2 - 9 } & No. & $\mathbf{\%}$ & No. & $\mathbf{\%}$ & No. & \% & No. & \% \\
\hline$<\mathbf{1 6}$ & 12 & 8.82 & - & - & - & - & 12 & 8.82 \\
$\mathbf{1 7 - 3 0 r}$ & - & - & 7 & 5.14 & 5 & 3.68 & 12 & 8.82 \\
$\mathbf{3 1 - 4 0}$ & - & - & 9 & 6.61 & 11 & 8.08 & 20 & 14.69 \\
$\mathbf{4 1 - 5 0}$ & - & - & 4 & 2.94 & 19 & 13.99 & 23 & 16.93 \\
$\mathbf{5 1 - 6 0}$ & - & - & 13 & 9.55 & 31 & 22.79 & 44 & 32.34 \\
$>\mathbf{6 1}$ & - & - & 8 & 5.90 & 17 & 12.5 & 25 & 18.40 \\
\hline Total & 12 & 8.82 & 41 & 30.14 & 83 & 61.02 & 136 & \\
\hline
\end{tabular}


Table (4): Mean and percentage of systemic disease and pathology

\begin{tabular}{|c|c|c|c|c|c|c|c|c|c|c|c|c|}
\hline \multirow{2}{*}{$\begin{array}{c}\text { Age } \\
\text { Group } \\
\text { (Years) }\end{array}$} & \multicolumn{2}{|c|}{ Diabetic } & \multicolumn{2}{|c|}{ Cardiac } & \multicolumn{2}{|c|}{$\begin{array}{c}\text { Bone } \\
\text { Pathology }\end{array}$} & \multicolumn{2}{|c|}{$\begin{array}{l}\text { Rheumatic } \\
\text { Diseases }\end{array}$} & \multicolumn{2}{|c|}{ Bleeding } & \multicolumn{2}{|c|}{ Total } \\
\hline & No. & $\%$ & No. & $\%$ & No. & $\%$ & No. & $\%$ & No. & $\%$ & No. & $\%$ \\
\hline$<16$ & - & - & - & - & - & - & - & - & - & - & - & - \\
\hline $17-30 r$ & 3 & 3.61 & - & - & 1 & 1.20 & - & - & 1 & 1.20 & 5 & 6.02 \\
\hline $31-40$ & 4 & 4.81 & 1 & 1.20 & 3 & 3.61 & - & - & 3 & 3.61 & 11 & 13.26 \\
\hline 41-50 & 8 & 9.63 & 6 & 7.22 & 5 & 6.02 & - & - & - & - & 19 & 22.89 \\
\hline 51-60 & 9 & 10.84 & 16 & 19.27 & 6 & 7.22 & - & - & - & - & 31 & 37.35 \\
\hline$>61$ & 5 & 6.02 & 9 & 10.84 & 1 & 1.20 & 2 & 2.40 & - & - & 17 & 20.48 \\
\hline Total & 29 & 34.93 & 32 & 38.55 & 16 & 19.27 & 2 & 2.40 & 4 & 4.81 & 83 & \\
\hline
\end{tabular}

Age $\square$ Patient Preference $\square$ Systemic Diseases

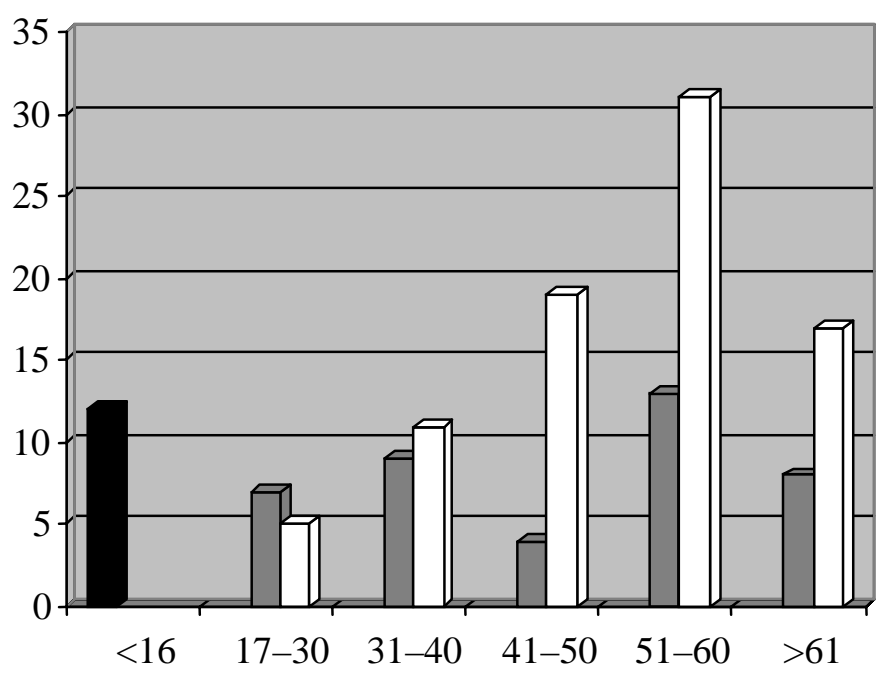

Figure (4): Relation between age, conservative and medical condition of the patient

Rheumatic Disease $\mathrm{O}_{\text {Bleeding }} \square_{\text {Bone Pathology }} \mathrm{B}_{\text {Cardiac }} \square_{\text {Diabetic }}$

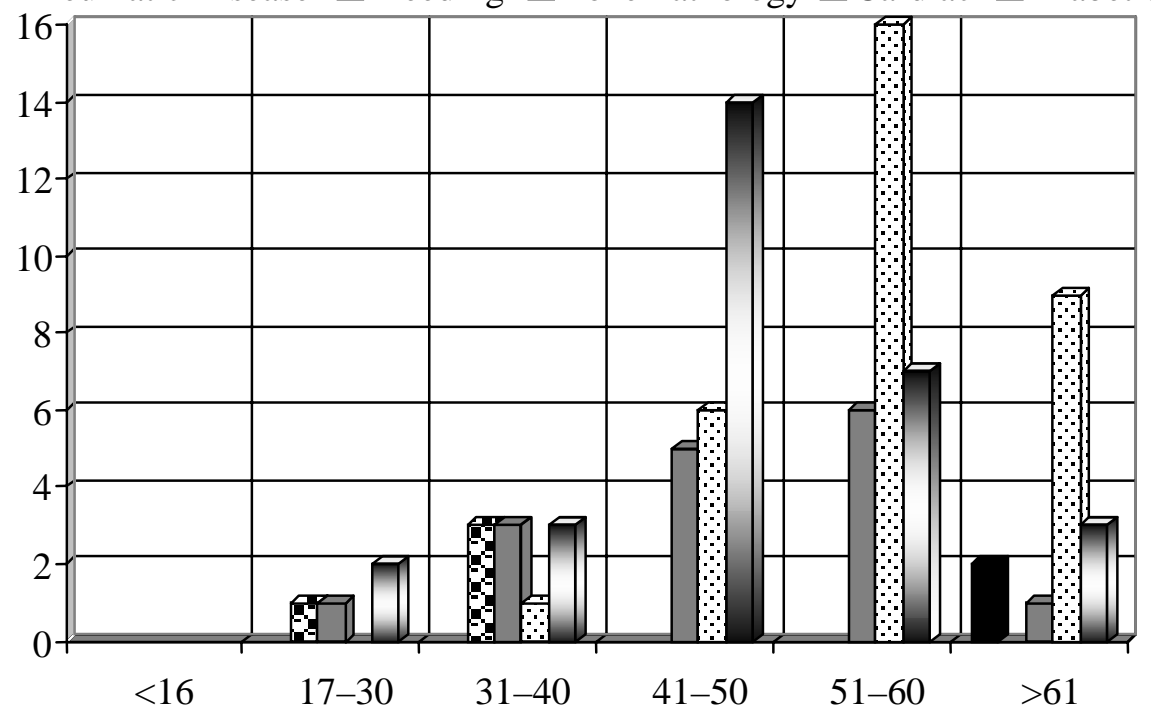

Figure (5): Number of patient with systemic diseases and pathology 
Table (5): Local factors

\begin{tabular}{ccccccccccc}
\hline $\begin{array}{c}\text { Age Group } \\
\text { (Years) }\end{array}$ & \multicolumn{2}{c}{ Oral Hygiene } & \multicolumn{2}{c}{$\begin{array}{c}\text { Bone } \\
\text { Measurement }\end{array}$} & \multicolumn{2}{c}{ Space } & \multicolumn{2}{c}{ Occlusion } & \multicolumn{2}{c}{ Total } \\
\cline { 2 - 12 } & $\mathbf{N o .}$ & $\mathbf{\%}$ & No. & $\mathbf{\%}$ & No. & $\mathbf{\%}$ & No. & $\mathbf{\%}$ & No. & \% \\
\hline$<\mathbf{1 6}$ & - & - & - & - & - & - & - & - & - & - \\
$\mathbf{1 7 - 3 0 r}$ & 6 & 5.04 & - & - & - & - & 1 & 0.84 & 7 & 5.88 \\
$\mathbf{3 1 - 4 0}$ & 7 & 5.88 & 8 & 6.72 & 2 & 1.68 & 3 & 2.52 & 20 & 16.80 \\
$\mathbf{4 1 - 5 0}$ & 14 & 11.76 & 12 & 10.08 & 7 & 5.88 & 2 & 1.68 & 35 & 29.41 \\
$\mathbf{5 1 - 6 0}$ & 19 & 15.96 & 15 & 12.60 & 5 & 4.20 & 6 & 5.04 & 45 & 37.81 \\
$>\mathbf{6 1}$ & 8 & 6.72 & 2 & 1.68 & 1 & 0.84 & 1 & 0.84 & 12 & 10.08 \\
\hline Total & 54 & 45.37 & 37 & 31.09 & 15 & 12.60 & 13 & 10.92 & 119 & \\
\hline
\end{tabular}

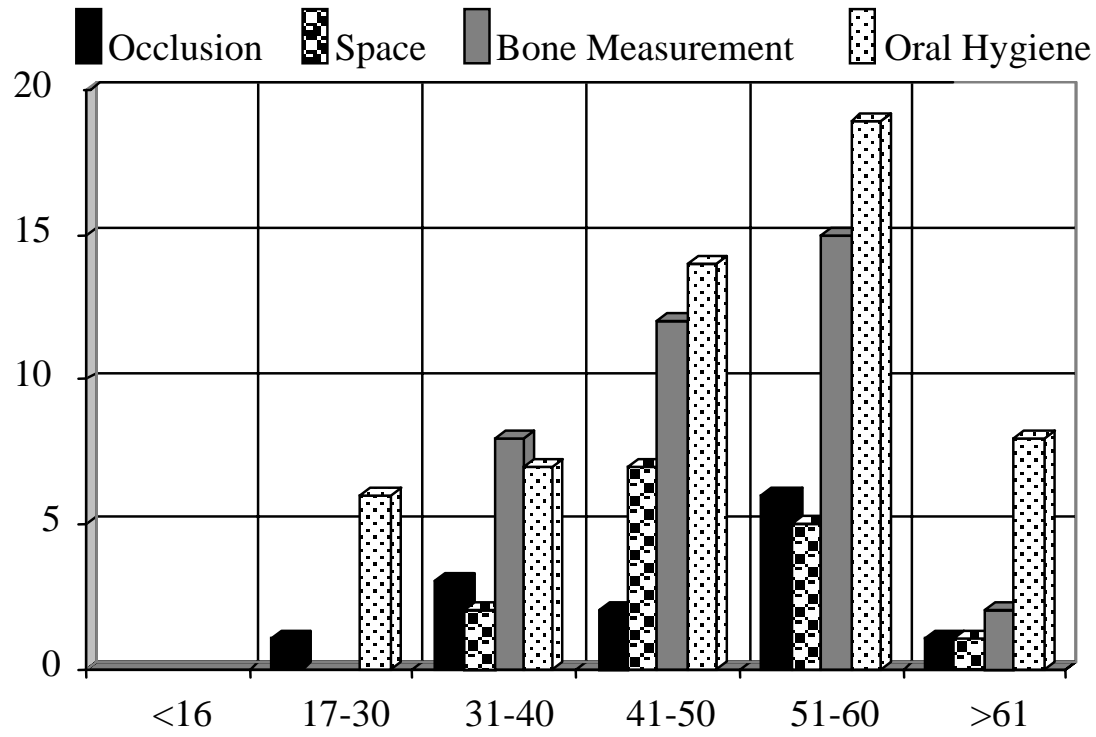

Figure (6): Number of patients with different local factors

Table (6): Number and percentage of education and economy of operated patients

\begin{tabular}{ccccc}
\hline \multirow{2}{*}{ Level } & \multicolumn{2}{c}{ Education } & \multicolumn{2}{c}{ Economy } \\
\cline { 2 - 5 } & No. & \% & No. & \% \\
\hline Level I & 24 & 53.33 & 26 & 57.77 \\
Level II & 19 & 42.22 & 18 & 40 \\
Level III & 2 & 4.44 & 1 & 2.22 \\
\hline
\end{tabular}

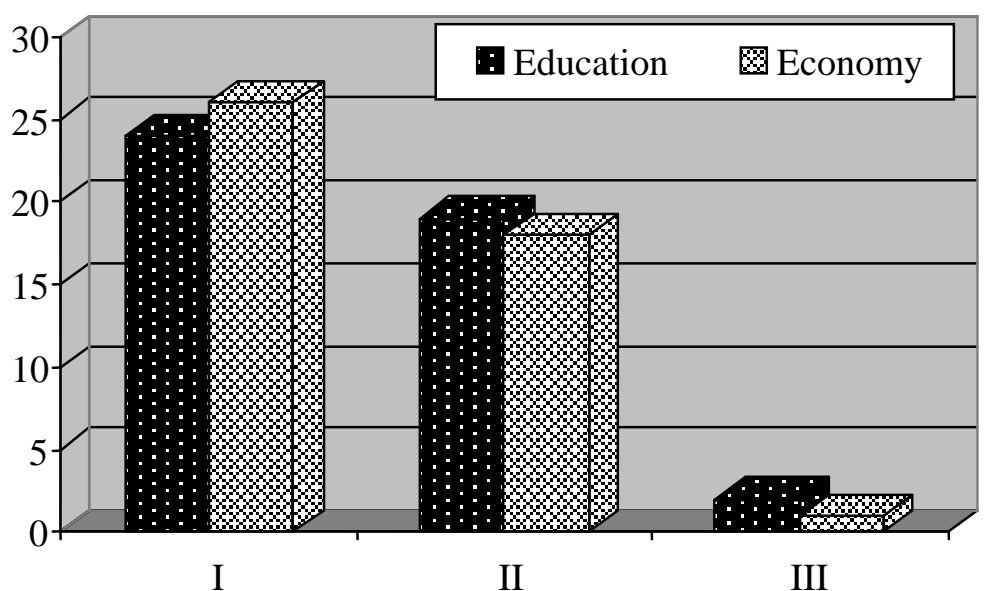

Figure (7): Level of Education and economy of operated patients 


\section{DISCUSSION}

\section{Age Incidence:}

Regarding age of the examined patients, those aged 17-40 years showed more than half of the total examined patients (66.65 \%). This high percentage is merely related to preference of this group; they prefer surgery over removable appliance or destructive bridge work, as well as they can tolerate surgical operation rather than younger or older age group.

The age group higher than 60 years was the least percent among the total examined patients (3.33 \%) as they don't prefer surgical work to already persistent conservative appliances.

In clinical analysis done by Noriko et al., ${ }^{(12)}$ for 462 operated patients, who found $76.6 \%$ were $40-69$ years of age, while Watson et al. ${ }^{(13)}$ found of total 117 patients, nearly $70 \%$ for the same age group. In this study for the total operated patients were $40 \%$ for the same age group.

\section{Gender Incidence:}

There were no definitive differences between male to female ratio, in that $55.33 \%$ were female while $44.66 \%$ were male from the total operated and non-operated patients. ${ }^{(14-16)}$

\section{Selection of Patients:}

There is no absolute contraindication for implant surgery, but there is a relative percentage of failure and success. So the selection of patients depended on the above listed special criteria organized in order to reduce the failure rate as much as possible. The age of patient, the preference of the patient to undergo surgical operation, and the systemic health were general factors for selection of an implant patient.

Forty-five percent of total were nonoperated due to general factors, medically unfit patients constituted the highest percentage among the other reasons. Diabetes and cardiac disease showed the highest percentage (73.48 \%) from other diseases which involved bone pathology, rheumatic disease, and bleeding.

Local factors made $39.6 \%$ of the total 300 patients. Among those, $45.37 \%$ were due to inconvenient oral hygiene. The rest distributed as inadequate alveolar bone, and inter-arch space and non-functioning occlusion.

\section{Economy and Education Incidence:}

The cost of a single unit implant with the supra-structure is (100\$) when compared with other types of restorations (removable dentures or bridges). So, the cost of single unit implant was on average 3 times more expensive than conventional types. Even this difference was considered better than that present outside Iraq, in that Jonsson et al ${ }^{(17)}$ stated that the implant cases were 7 times more expensive, and MacEntee and Walton ${ }^{(18)}$ showed that 5-12 times more expensive. Most of our patients were with high socio-economic level and high education level.

\section{CONCLUSION}

In comparison between operated and non-operated patients, the higher age groups were 17-30 years showed 5.33\%, while in non-operated patients 51-60 years showed 29.66\%. Female patients (55.33\%) seeking implant surgery, $30.14 \%$ preferred conservative work than surgery. Most of our patients were above 50 years being apprehensive from surgical work.

The result of this study showed high percentage (38.55\%) of medically unfit patients with cardiac disease. Bad oral hygiene constituted the highest percentage among the other local factors. Low percentage of educational levels and economical levels of patients need an explanation about surgical and prosthetic parts of dental implant.

\section{REFERENCES}

1. Academy of Prosthodontics. The glossary of prosthodontic terms. $J$ Prosthet Dent. 2005; 94: 10-81.

2. Mckinney RV. Contemporary Implant Dentistry. Part II. $1^{\text {st }}$ ed. Mosby Co. London. 1993; Pp: 355-390.

3. Misch CE. Implant Treatment. Contemporary Implant Dentistry. $1^{\text {st }}$ ed. Yearbook Mosby Co. St Louis. 1993. Pp: 103-122.

4. Small IA, Misiek DJ. A 16-years evaluation of the mandibular stable bone plate. J Oral Maxillofac Surg. 1984; 42: 421-428. 
5. Schroeder A, Buser F. A Brief History of Implantology. The ITI System. Mosby Co. St Louis. 1996; Pp: 3-17.

6. Misch CE. Rationale for Implants. Contemporary of Implant Dentistry. $2^{\text {nd }}$ ed. Mosby Co. London. 1999; Pp: 3-17.

7. Kokat AM, Akea K. Fabrication of a screw-retained fixed provisional prosthesis supported by dental implants. $J$ Prosthet Dent. 2004; 91: 293-297.

8. Misch CE. Patient Evaluation Booklets. Plattsburgh. New York. 1994; Pp: 9-11.

9. Beikler T, Flemming TF. Implants in the medically compromised patient. Crit Rev Oral Biol Med. 2003; 14: 305316.

10. Mitchell L, Mitchell DA. Oxford Handbook of Clinical Dentistry. $3^{\text {rd }}$ ed. Oxford University Press. Oxford. 1999; Pp: 432-433.

11. Lekholm U. The Surgical Site. $2^{\text {nd }}$ ed. Mosby Co. St Louis. 1997; Pp: 889962.

12. Noriko T, Kento T, Tsuneji O, Motohiro M, Kozue M, Makoto S, Shohei K. A clinical study on unfavorable cases of dental implant. Kokubyo Gakkai Zasshi. 2003; 70: 182-189.

13. Watson R., Marinello C, Kjellman O, Rundcrantz T, Fahraeus J, Lithner B.
Do healing abutments influence the outcome of implant treatment? A threeyear multicenter study. $J$ Prosthet Dent. 1998; 79: 193-198.

14. Bragger U, Karoussis L, Persson R, Pjetursson B, Salvi G, Lang NP. Technical and biological complications/failures with single crowns and fixed partial dentures on implants: A 10-year prospective cohort study. Clin Oral Implants Res. 2005; 16: 326-334.

15. Neviens M, Mellonig J, Reiser G, Buser D. Implants in regenerated bone: Long-term survival. Int J Periodont Restor Dent. 1998; 18: 35-45.

16. Cune DW. Immediate labial contour restoration for improved esthetics: A radiographic study on bone splitting in anterior single-tooth replacement. Int $J$ Oral Maxillofac Implants. 1997; 12: 686-696.

17. Jonsson B, Karlsson G. Cost benefits evaluation of dental implants. Int J Technol Assess Health Care. 1990; 6: 545557.

18. MacEntee MI, Walton JN. The economics of complete dentures and implant-related services. A framework for analysis and preliminary outcomes. $J$ Prosthet Dent. 1998; 79: 24-30. 